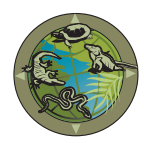

\title{
Selective Predation by Feral Cats on a Native Skink on Guam
}

Björn Lardner ${ }^{1}$, Robert N. Reed ${ }^{2}$, Amy A. Yackel Adams ${ }^{2}$, MJ Mazurek ${ }^{3}$,

Thomas J. Hinkle ${ }^{3}$, Patricia M. Levasseur ${ }^{3}$, Meredith S. Palmer ${ }^{3}$, and Julie A. Savidge ${ }^{1}$

${ }^{1}$ Department of Fish, Wildlife, and Conservation Biology, Colorado State University, Fort Collins, Colorado 80523-1484, USA

(Bjorn.Lardner@ColoState.edu, Julie.Savidge@ColoState.edu)

${ }^{2}$ U.S. Geological Survey, Fort Collins Science Center, 2150 Centre Avenue, Building C, Fort Collins, Colorado 80526-8118, USA (reedr@usgs.gov, yackela@usgs.gov)

${ }^{3}$ Dynamac Corporation under contract to U.S. Geological Survey, Fort Collins Science Center, 2150 Centre Avenue, Building C, Fort Collins, Colorado 80526-8118, USA (mmazurek@usgs.gov, thomas_hinkle@usgs.gov, pmlevasseur@gmail.com, mspalmer.zool@gmail.com)

Photographs by the senior author.

Two species of skinks (Fig. 1) occur in a 5-ha plot on Guam where we have been conducting intensive research on Brown Treesnake (Boiga irregularis) population biology for nearly a decade (Rodda et al. 2007). The Pacific Blue-tailed Skink (Emoia caeruleocauda [de Vis 1892]) is native to Guam, whereas the Curious Skink (Carlia ailanpalai Zug 2004) is

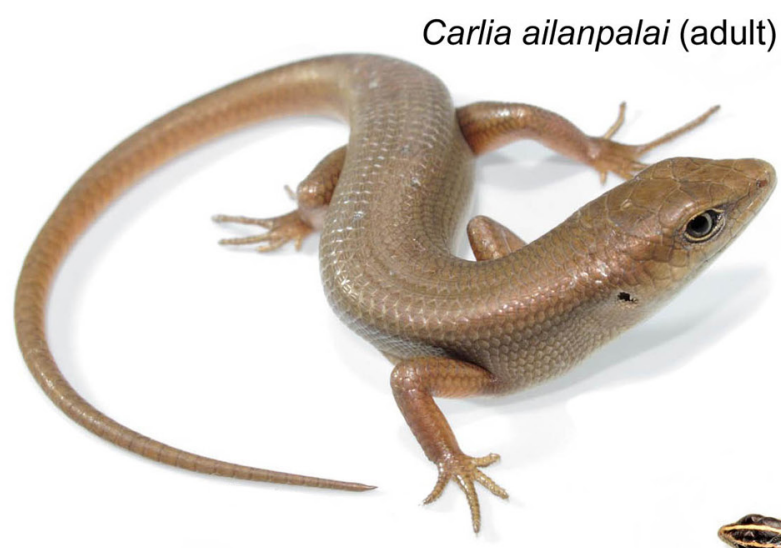

Emoia caeruleocauda (adult)
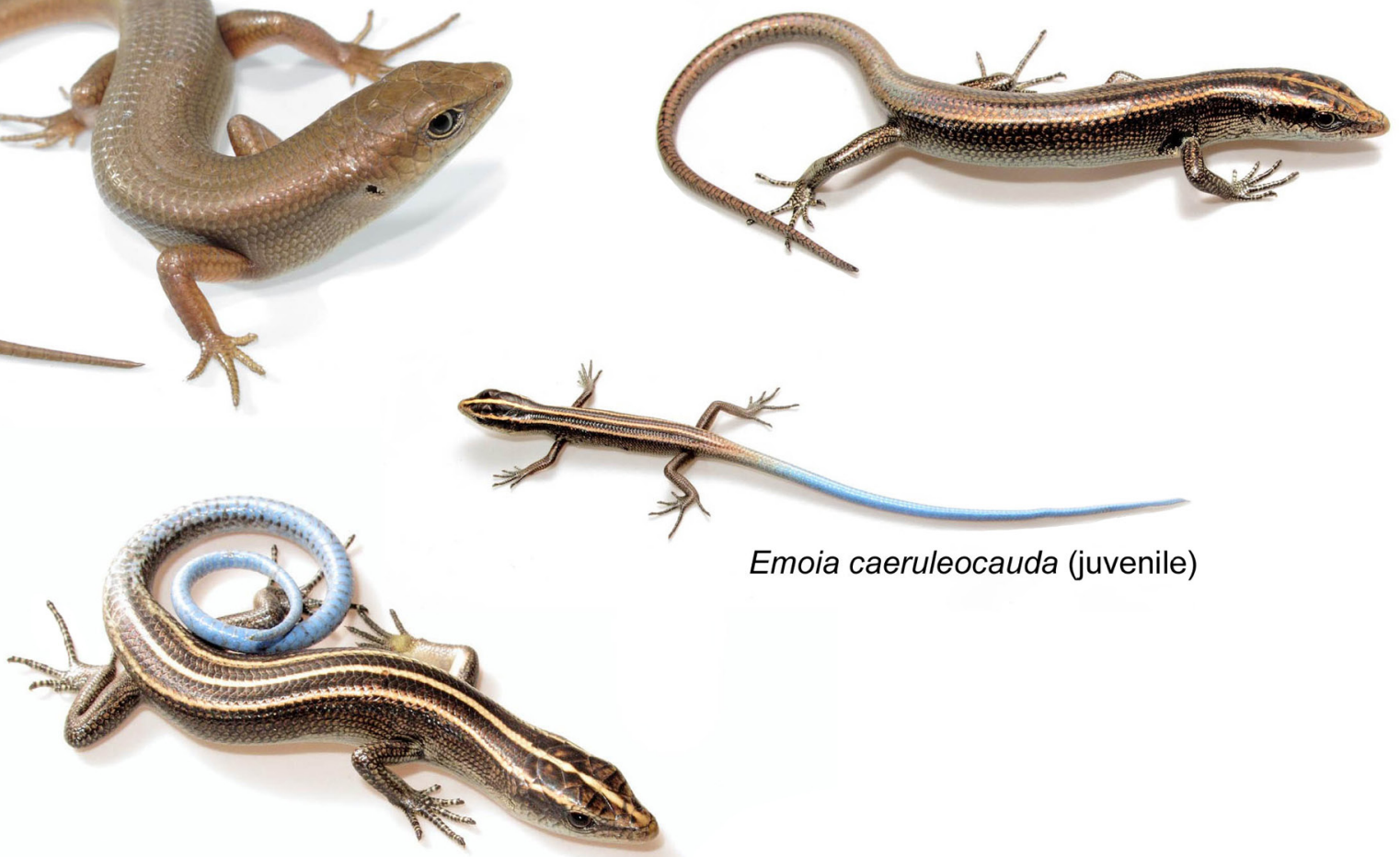

Emoia caeruleocauda (juvenile)

Emoia caeruleocauda (subadult)

Fig. 1. The Curious Skink (Carlia ailanpalai) is native to the Bismarck Archipelago off the northeastern coast of New Guinea, but has been introduced to and become established in several of the Mariana Islands (including Guam) as well as other parts of Micronesia. Juvenile Pacific Blue-tailed Skinks (Emoia caeruleocauda) have a striped body and a blue tail; subadults also have a striped body, but the blue tail gradually turns brown. Adults eventually lose the stripes and the black body turns dull grayish brown; this adult still retains traces of the dorsal stripes. 


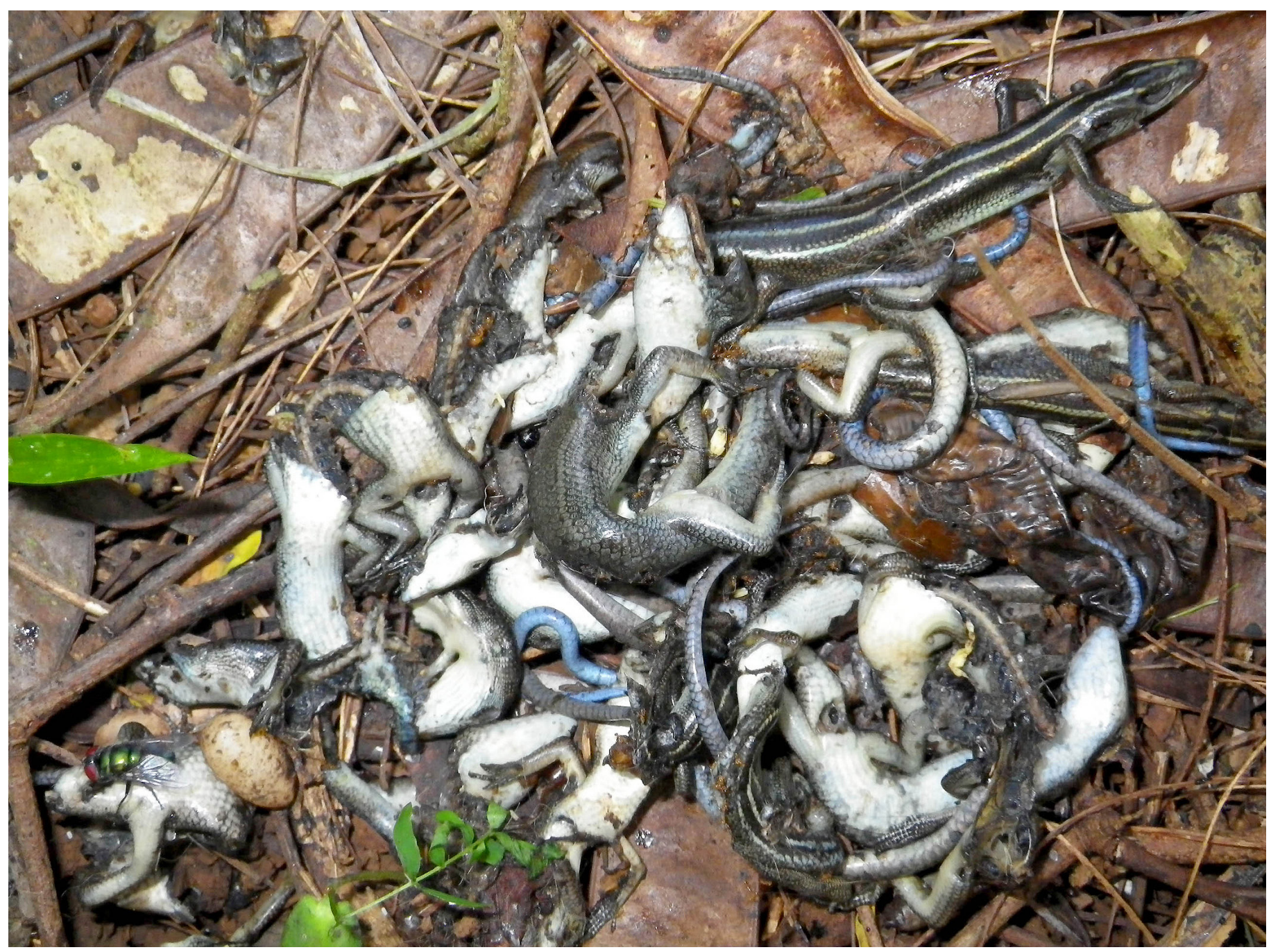

Fig. 2. A pile containing some of the at least 28 vomited Emoia caeruleocauda, photographed in situ when collected on 28 November 2012 . Note a skink egg in lower left side of photograph.

invasive. On the evening of 27 November 2012, PML and MSP discovered a pile of vomited skinks (Fig. 2) inside the plot (UTM 55P: $269125 \mathrm{~m} \mathrm{E,} 1508930 \mathrm{~m} \mathrm{~N}$ ). The majority of the bodies were severed into multiple pieces. Many of the lizards had been eaten soon before they were vomited, as most body parts exhibited little evidence of digestion. We positively identified 28 E. caeruleocauda by the distinctively striped juvenile/subadult pattern or the presence of five (not four) digits on the front limbs. Two other severed heads were not identified with certainty, but we suspect both were $E$. caeruleocauda. Most notably, none of the lizard parts (Fig. 3) showed any characteristics of $C$. ailanpalai, the only other skink present at the site. All remains were deposited with the National Museum of Natural History (Acc. No. 2063055, USNM 580665-580691, plus an associated jar with body parts not assignable to any specific specimen).

The 5-ha plot is surrounded by a $1.5-\mathrm{m}$ fence made of hardware cloth that prevents immigration/emigration of snakes, but does not prevent entry of feral cats (Felis catus
Linnaeus 1758) or Mangrove Monitors (Varanus indicus Daudin 1802), which are the only non-avian predators on Guam capable of accessing this area. Among the skink remains, we found mammalian hairs that were microscopically examined and compared to previously collected hair samples from the sole small mammalian species present at the site, Rattus cf. diardii (Jentink 1880) (Wiewel et al. 2009a, b; pers. obs.). The hair was morphologically distinct from the rat hair samples but was consistent with cat hair morphology in medullary pattern, root structure, and degree of pigmentation (Hausman 1920, http://www.microlabgallery.com/gallery/ CatTabby1dMedulaStructure.aspx).

Both feral cats and monitors eat lizards (Dryden 1965, McCoid and Witteman 1993, Nogales et al. 2004, Reardon et al. 2012) and monitors may vomit a meal (Wostl et al. 2011). However, monitors lack the dentition to cleanly sever legs and other body parts from skinks as was observed in the vomited remains. Moreover, monitors the size of $V$. indicus (SVL rarely $>0.5 \mathrm{~m}$; Wikramanayake and Dryden 1988) are 


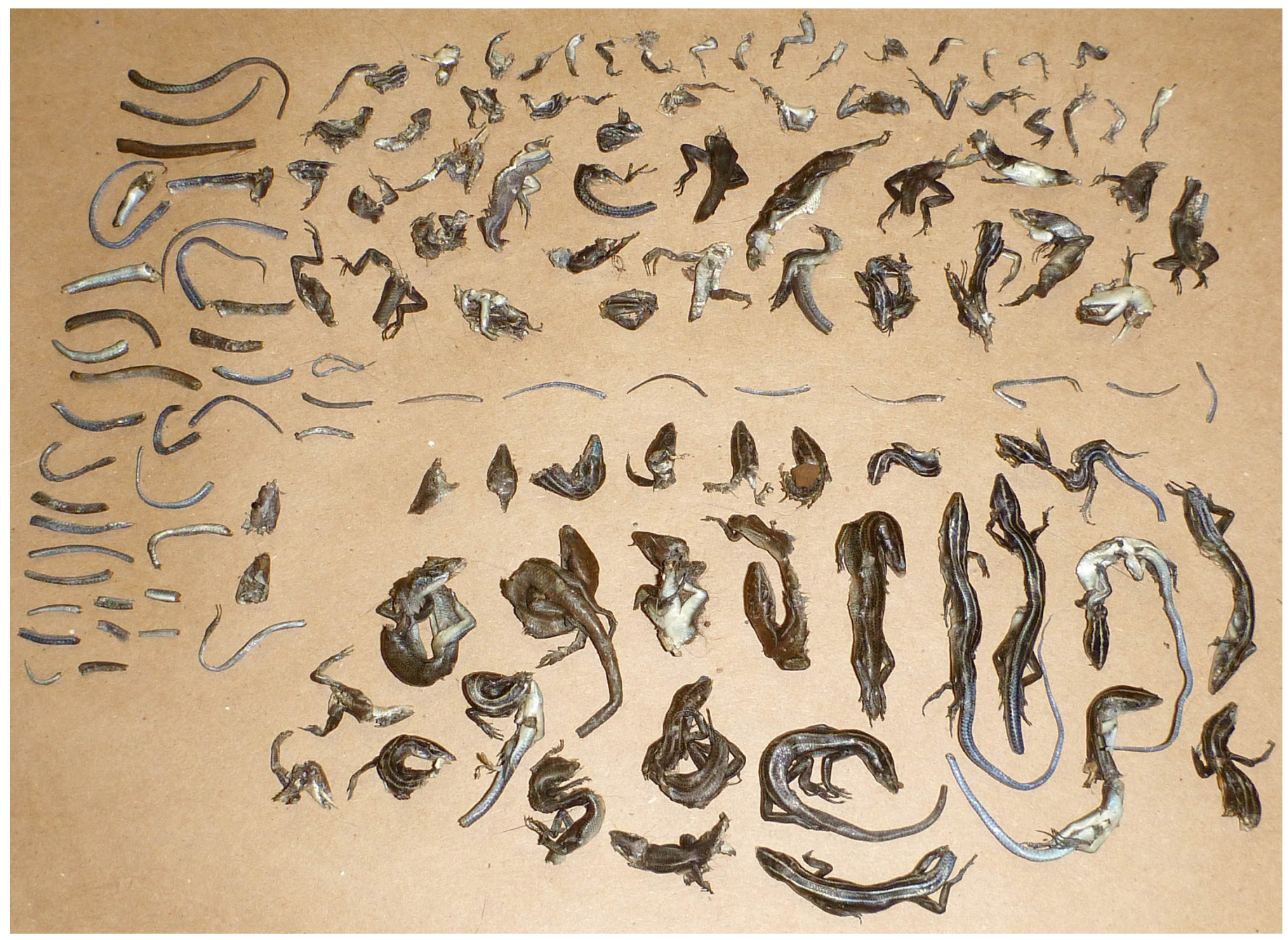

Fig. 3. Separated remains of the skinks collected on 28 November 2012. Two skink eggs also among the remains are not shown.

unlikely to prey on cats. The remains were clearly not vomited by a Brown Treesnake, as these snakes ingest prey whole. Thus, because the hair among the vomited skinks came from a cat, cats often ingest their own fur when grooming themselves, and no avian predators in Guam prey on cats, we concluded that a cat ate and vomited the skinks.

On the evening of 13 December 2012, TJH (together with R.G. Lechalk) found another pile of vomited skinks ca. $70 \mathrm{~m}$ from the previous pile, also inside the fenced plot. Visual inspection (in the field) allowed us to positively identify 10 E. caeruleocauda and three C. ailanpalai. As with the previous observation, some lizards were severed into multiple pieces and others were relatively intact. Puncture-like marks assumed to be from teeth were observed on some lizard bodies. These remains were not collected but we assume that a cat was again the culprit.

We have conducted annual (2005-2008) or semiannual (2008 to present) skink surveys at this site using sticky traps placed on the ground (see Rodda et al. 1993). On 24-25 September 2012, such a survey yielded 208 E. caeruleocanda and 212 C. ailanpalai. Given the similar trap-capture rates across species, the biased ratio of vomited skinks favoring E. caeruleocauda is striking. With a relative abundance of 208:212 and assuming independence of captures, the chances of a non-selective predator randomly "sampling" only E. caeruleocauda when ingesting 28 ground-dwelling skinks (28 is the number we could positively identify) is $(208 / 420)^{28}=$ $2.85 \times 10^{-9}$, or odds of $1: 350,000,000$. Given that trap-capture rates of the two skinks were very similar, we may more conservatively ask what are the chances that all ingested lizards were of one species only, i.e., either 28:0 (only E. caeruleocauda) or 0:28 (only C. ailanpalai). That probability equals $\left[(208 / 420)^{28}+(212 / 420)^{28}\right]=7.7 \times 10^{-9}$, or $1: 130,000,000$. Considering the remains found on 13 December, the probability of randomly sampling no more than three $C$. ailanpalai out of 13 ground-dwelling skinks is, of course, much higher: 0.043 (i.e., odds of 1:23).

These observations support the hypothesis that feral cats are capable of highly selective predation on a native skink. Both the native and exotic skink species exhibit similar adult 
body lengths, but $C$. ailanpalai attains almost twice the body mass of E. caeruleocauda (Campbell et al. 2012). We would not expect that being more heavy-bodied would enhance predator avoidance. Also, C. ailanpalai is locally known as the Curious Skink, a name given for its habit of approaching and investigating any movement or sound. If anything, such a habit might make them more, not less, susceptible to predation. Juvenile and subadult E. caeruleocauda have blue tails, which could be a cue incorporated in a predator's search image. Cats appear to have sufficiently good color vision to allow them to cue in on blue tails (Sechzer and Brown 1964, Guenther and Zrenner 1993). However, a few of the E. caeruleocauda found on 27 November were large enough to have the dull brown-gray tails typical of large adults (Fig. 2).

The two skink species also differ in the range of microhabitats they use. Both forage on the ground. However, $E$. caeruleocauda readily climbs both herbaceous vegetation and trees, whereas C. ailanpalai is largely terrestrial (pers. obs.). Both are diurnal, and whereas $C$. ailanpalai sleeps on the ground at night (among dense vegetation, or under leaves, logs, or other objects), we occasionally see E. caeruleocauda sleeping arboreally in clumps of dry or wilted leaves. Given that both piles of remains were found in the early evening (3 h vs. 1 h 10 min after sunset, respectively), and some of the skinks were minimally digested, they likely had been captured while active in daylight hours. While the reason(s) for the highly selective predation on E. caeruleocauda is not clear, a predator search image for brightly colored tails is a plausible hypothesis. A bright blue tail in juvenile lizards might have a selective advantage by attracting visually guided predators to the tail rather than the body, allowing the lizard to sacrifice the tail by autotomy while saving its life (Hawlena et al. 2006). This seems intuitively plausible if the predator is a bird that pecks with a bill. Also, bright colors in animals may be aposematic, suggesting to a predator that the prey is noxious or toxic (Wallace 1866). Much anecdotal evidence on the Internet suggests that certain skinks with blue tails (e.g. the North American Plestiodon [Eumeces] inexpectatus (Taylor 1932)) might be toxic to cats, causing neurological symptoms that may be severe or even lethal. Vomiting is one of the reported symptoms. However, scientific evidence for such toxicity is scarce (Hausman 2006, de Lahunta and Glass 2008). If Emoia caeruleocauda is toxic to cats, that could explain why these skinks were thrown up. That a cat, after ingesting two species of skinks, could selectively throw up prey of one species only is unlikely — and our second observation tends to support that notion. Regardless if the evolution of a blue tail in this skink is due to a selective advantage by diversion from the body or due to aposematism, our observation suggests a blue tail is a liability when faced with feral cats.

\section{Acknowledgments}

Skink trapping was conducted under Colorado State University IACUC 12-3632A. Funding for fieldwork was provided by the U.S. Department of the Interior's Office of Insular Affairs. We thank Brian Cade for comments on an earlier version of this manuscript.

\section{Literature Cited}

Campbell, E.W., A.A. Yackel Adams, S.J. Converse, T.J. Fritts, and G.H. Rodda. 2012. Do predators control prey species abundance? An experimental test with Brown Treesnakes on Guam. Ecology 93:1194-1203.

de Lahunta, A. and E. Glass. 2008. Veterinary Neuroanatomy and Clinical Neurology. 3rd ed. Saunders/Elsevier, St. Louis, Missouri.

Dryden, G.L. 1965. The food and feeding habits of Varanus indicus on Guam. Micronesica 2:73-76.

Guenther, E. and E. Zrenner. 1993. The spectral sensitivity of dark- and lightadapted cat retinal ganglion cells. The Journal of Neuroscience 73:1543-1550.

Hausman, G. 2006. The war between cats and skinks. Gulfshore Life (May 2006):195-198.

Hausman, L.A. 1920. Structural characteristics of the hair of mammals. The American Naturalist 635:496-523.

Hawlena D., R. Boochnik, Z. Abramsky, and A. Bouskila. 2006. Blue tail and striped body: Why do lizards change their infant costume when growing up? Behavioral Ecology 17:889-896.

McCoid, M.J. and G.J. Witteman. 1993. Varanus indicus (Mangrove Monitor). Diet. Herpetological Review 24:105.

Nogales, M., A. Martín, B.R. Tershy, C.J. Donlan, D. Veitch, N. Puerta, B. Wood, and J. Alonso. 2004. A review of feral cat eradication on islands. Conservation Biology 18:310-319.

Reardon, J.T., N. Whitmore, K.M. Holmes, L.M. Judd, A.D. Hutcheon, G. Norbury, and D.I. Mackenzie. 2012. Predator control allows critically endangered lizards to recover on mainland New Zealand. New Zealand Journal of Ecology 36:141-150.

Rodda, G.H., J.A. Savidge, C.L. Tyrrell, M.T. Christy, and A.R. Ellingson. 2007. Size bias in visual searches and trapping of Brown Treesnakes on Guam. The Journal of Wildlife Management 71:656-661.

Rodda, G.H., M.J. McCoid, and T.H. Fritts. 1993. Adhesive trapping II. Herpetological Review 24:99-100.

Sechzer, J.A. and J.L. Brown. 1964. Color Discrimination in the cat. Science 144:427-429.

Wallace, A.R. 1866. On reversed sexual characters in a butterfly, and its interpretation on the theory of modification and adaptive mimicry, pp. 186-187. In: W.T. Robertson (ed.), The British Association for the Advancement of Science, Nottingham Meeting, August, 1866: Report of the papers, discussions, and general proceedings. T. Forman, Nottingham, Great Britain, and R. Hardwicke, London, Great Britain (http://wallace-online.org/converted/pdf/1866_ Association_S121.pdf).

Wiewel, A.S., A.A. Yackel Adams, and G.H. Rodda. 2009a. Evaluating abundance estimate precision and the assumptions of a count-based index for small mammals. The Journal of Wildlife Management 73:761-771.

Wiewel, A.S., A.A. Yackel Adams, and G.H. Rodda. 2009b. Distribution, density, and biomass of introduced small mammals in the southern Mariana Islands. Pacific Science 63:205-222.

Wikramanayake, E.D. and G.L. Dryden. 1988. The reproductive ecology of Varanus indicus on Guam. Herpetologica 44:338-344.

Wostl, E., T.J. Hinkle, B. Lardner, and R.N. Reed. 2011. Boiga irregularis (Brown Treesnake). Predation and diet. Herpetological Review 42:282. 